\title{
Overturning stability of supported geomembrane tube for flood control
}

\author{
Xin Gao ${ }^{1,2}$, Liqiang Sun ${ }^{1,2}$, Wei Guo ${ }^{1,2^{*}}$, Ruxiao Ren ${ }^{1,2}$, Wenqian Zeng ${ }^{1,2}$ \\ ${ }^{1}$ State Key Laboratory of Hydraulic Engineering Simulation and Safety in Tianjin University, Tianjin 300072, China \\ ${ }^{2}$ School of Civil Engineering, Tianjin University, Tianjin 300072, China
}

\begin{abstract}
As a kind of rapid filling hydraulic structure, geomembrane tube can effectively act as flood barriers and cofferdams for flood risk management. L-shaped block is used to support geomembrane tube to prevent it from rolling. The contact force between the L-shaped block and the geomembrane tube is analyzed by using particle flow code $\left(\mathrm{PFC}^{2 \mathrm{D}}\right)$ software, and the overturning stability of the L-shaped block is calculated. The relationship between the key factors and the overturning stability was established. It is found that the central angle of the L-shaped block has little influence on the overturning stability. The overturning stability decreases with the increase of the initial pumping pressure. Keeping $L_{\mathrm{w}} / L_{\mathrm{b}}$ unchanged, increasing $\mathrm{Lb}$ will improve the overturning stability where $L_{\mathrm{w}}$ and $L_{\mathrm{b}}$ are the width and the height of the Lshaped block. Under the ultimate water level, when $1.23 L_{\mathrm{bcr}}<L_{\mathrm{w}} \leq 1.55 L_{\mathrm{bcr}}$, the L-shaped block is in the state of overturning stability where $L_{\text {bcr }}$ is the critical height of the L-shaped block. The initial pumping pressure is less than $0.152 \gamma L$, the L-shaped block is in the state of overturning stability with $L_{\mathrm{w}} / L_{\mathrm{bcr}}=1.0$ where $\mathrm{L}$ is the cross-sectional perimeter of the geomembrane tube and $\gamma$ is the unit weight of the filling liquid, on the contrary, $L_{\mathrm{w}} / L_{\mathrm{bcr}}$ must be greater than 1 to ensure its overturning stability.
\end{abstract}

\section{Introduction}

Flood disasters gradually tend to be more frequent and intensive, causing heavy losses to urban underground facilities and aboveground buildings. With the rapid development of the water conservancy industry, there is an urgent need to further improve flood control measures and enhance the emergency response capabilities for flood control. Traditional flood-fighting measures mainly use manpower to fill sandbags to construct flood barriers and cofferdams, which have poor timeliness and high cost. Geomembrane tubes are easy to construct and are compatible with the environment, and can be filled quickly and recycled after the flood recedes; therefore, they are efficiently applied to temporary flood fighting (Biggar \& Masala, 1998; Fowler, 1997).

A lot of analytical solutions have been proposed to studied the cross-sectional shape and the tensile force of the geomembrane tubes resting on rigid foundation (Leshchinsky, Leshchinsky, Ling, and Gilbert,1996; Plaut and Suherman,1998; Cantré and Saathoff,2011). The effects of the foundation strength and solid-liquid fillings on the cross-sectional shape and tensile force of the geomembrane tube have been examined (Guo, Chu, and Nie,2014; Guo, Chu, Yan, and Nie,2013; Guo, Chu, and Yan, 2011; Plaut, and Klusman, 1999). When the geomembrane tube be filled with silt, the consolidation stress and deformation characteristics of the silt have also been analyzed by Cantré (2002). The Mathematica have been applied to study the geometric characteristics and tensile force of the geomembrane tube placed on rigid foundation with arbitrary geometry (Ghavanloo, and Daneshmand, 2008). In addition, the geometric shape and tensile force of the geomembrane tube filled with nonuniform materials are also studied (Malík,2007; Malik, and Stanislav,2010). The above analysis methods assume that the geomembrane tubes are long enough and placed on a rigid basis, which can be simplified to a plane strain problem and the impact of friction can be ignored.

When geomembrane tubes are utilized for flood fighting, which tend to rolling off and lose their waterretaining function under the action of external water level. A series of supporting measures is also put forward to improve the stability of the geomembrane tube. The earliest method is to fix a wedge in the downstream of the geomembrane tube to get the geomembrane tube stuck (Plaut, and Klusman,1999). The finite-difference software $\left(\mathrm{FLAC}^{2 \mathrm{D}}\right)$ was used to study the wedged geomembrane tube (Huong, Plaut, and Filz, 2002). Using of an apron to stabilize geomembrane tubes(Kim, Freeman,et al., 2004), Stacking geomembrane tubes for flood control(Kim, Moler et al.,2005b) and Twochambered water filled geomembrane tubes used as water barriers(Kim, Filz, and Plaut, 2005), the FLAC software is used in the research of the above-mentioned different supporting structures. The biggest shortcoming of the FLAC software is that the bending moment can not be ignored.

\footnotetext{
$\overline{\text { *Corresponding author: guow@tju.edu.cn }}$
} 
The particle flow code $\left(\mathrm{PFC}^{2 \mathrm{D}}\right)$ can serve as an alternative method to analyse the geomembrane tube, which can get rid of the influence of the bending moment on the results. Based on $\mathrm{PFC}^{2 \mathrm{D}}$, the stability of wedged geomembrane tube and L-shaped geomembrane tube in retaining water have been investigated (Sun, Yue, and Guo, 2017; Sun, Qi, Gao, Guo, and Zhang,2019), which found that the L-shaped block was better than other structural types in the retaining water process. In the above studies, the water-retaining performance of the geomembrane tube system is usually studied under the condition that the support structure is fixed.

Numerical analyses using $\mathrm{PFC}^{2 \mathrm{D}}$ was conducted to establish a calculation model to investigate the performance of the L-shaped block. The numerical model has been verified by comparison with the existing experimental, theoretical and numerical results. According to the contact force between the L-shaped block and the geomembrane tube, the calculation method of contact stress and overturning stability will be put forward to study the performance of the L-shape block. The relationship between the overturning stability coefficient and the filling pressure, the central angle, the height and width of the L-shaped block were studied, and a simplified calculation method for overturning stability coefficient was established.

\section{Research Method}

Using the $\mathrm{PFC}^{2 \mathrm{D}}$ program to simulate geomembrane tube can effectively eliminate the impact of the bending moment between the units. According to the internal hydraulic pressure and lateral water pressure acting on the surface of the geomembrane tube, the force and deformation characteristics of the geomembrane tube can be truly simulated.

\subsection{Model Establishment and Calculation Process}

In order to apply the calculation results to general situations, the nondimensional parameters are adopted in this calculation. The normalized filling pressure is $p_{0} / \gamma L$, where $p_{0}$ is the filling pressure, $\gamma$ is the unit weight of the filling water and $L$ is the perimeter of the geomembrane tube. The normalized critical water level is $H_{\mathrm{cr}} / L$. The normalized height and width of the geomembrane tube are $H / L$ and $B / L$ respectively. The normalized height and width of the $\mathrm{L}$-shaped block are $L_{\mathrm{b}} / L$ and $L_{\mathrm{w}} / L$ respectively, the central angle of the L-shaped block is $\alpha$. The geomembrane tube and the L-shaped block are placed on a rigid foundation with sufficient rigidity and almost no deformation. The geometric model mainly includes the L-shaped block, the geomembrane tube and the rigid foundation. The load model mainly includes the filling pressure and the lateral water pressure. The geometric model and sizes are shown in Figure 1.

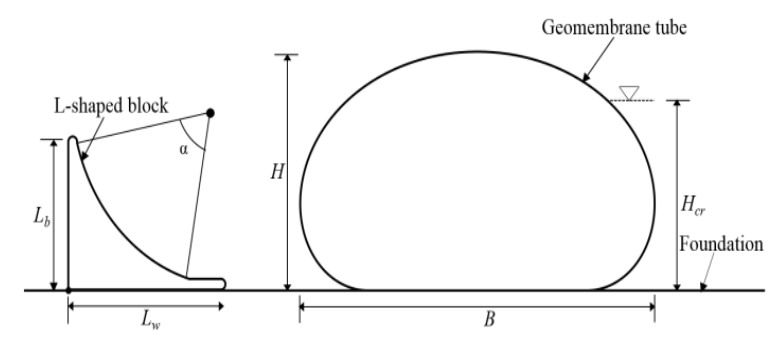

Fig.1. Parameter definition of geometric dimensions

The BALL command will be used to build the geomembrane tube and the block, the WALL command will be used to generate the rigid foundation, and then, the FIX command be used to fix the block unit.

The initial state of the numerical model is shown in Figure 2(a). Since all parameters are dimensionless, the unit weight $\gamma$ and the geomembrane tube perimeter $L$ are set to 1.0 in the numerical simulation. The geomembrane tube is composed of 500 rigid balls with diameter of 0.002 and unit weight of 1.4. The ball elements are connected through a point contact connection model, and the contact keys can only transmit force, not bending moment. The values of the other parameters in the numerical model are shown in Table 1.

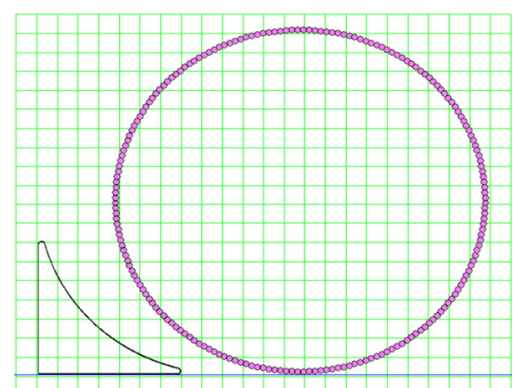

(a) Initial state of the balls and walls of the system

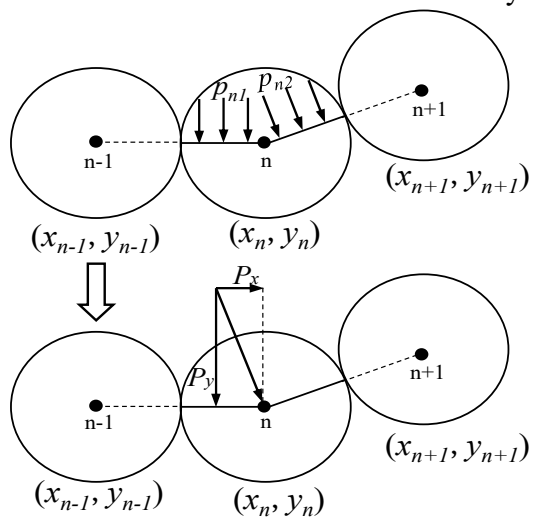

(b) Method of transforming hydraulic pressures to point loads

Fig.2. Numerical model of the L-shaped geomembrane tube

The central explicit finite difference method is used for calculation, and the position and force of each element are continuously updated at each time step until each element reaches an equilibrium state. In order to carry out the numerical calculation, the nodal load conversion method is applied to convert the surface load equivalently to the point load on the nodes. The node position is taken at the center of the particle as shown in Figure 2(b). According to the water pressure of adjacent units, the horizontal and vertical components of the point 
load on the unit are obtained, as shown in Equations (1) (4).

$$
\begin{aligned}
& p_{n 1}=p_{0}+\gamma\left[H-\left(y_{n}-\frac{y_{n}-y_{n-1}}{4}\right)\right] \\
& p_{n 2}=p_{0}+\gamma\left[H-\left(y_{n}+\frac{y_{n+1}-y_{n}}{4}\right)\right] \\
& P_{\mathrm{x}}=p_{n 2}\left(\frac{y_{n+1}-y_{n}}{2}\right)+p_{n 1}\left(\frac{y_{n}-y_{n-1}}{2}\right) \\
& P_{\mathrm{y}}=p_{n 2}\left(\frac{x_{n+1}-x_{n}}{2}\right)+p_{n 1}\left(\frac{x_{n}-x_{n-1}}{2}\right)
\end{aligned}
$$

Where $\gamma$ is the unit weight of filling water; $H$ is the height of geomembrane tube; $p_{0}$ is the filling pressure; $p_{\mathrm{n} 1}$ and $p_{\mathrm{n} 2}$ are the water pressures acting on adjacent units; $P_{x}$ is the equivalent horizontal point force; $P_{y}$ is the equivalent vertical point force.

Table 1. Parameters used in $\mathrm{PFC}^{2 \mathrm{D}}$ simulation

\begin{tabular}{|c|c|}
\hline name & values \\
\hline Unit weight of filling material & 1 \\
\hline Unit weight of ball & 1.4 \\
\hline Ball diameter for geomembrane tube & 0.002 \\
\hline Ball normal stiffness for geomembrane tube & $5.80 \mathrm{E}+06$ \\
\hline Ball shear stiffness for geomembrane tube & $5.80 \mathrm{E}+06$ \\
\hline Ball normal stiffness for block & $1.08 \mathrm{E}+11$ \\
\hline Ball shear stiffness for block & $1.08 \mathrm{E}+11$ \\
\hline Contact normal strength & $1.00 \mathrm{E}+06$ \\
\hline Contact shear strength & $1.00 \mathrm{E}+06$ \\
\hline Friction coefficient between ball and wall & 0.30 \\
\hline Contact normal stiffness & $5.00 \mathrm{E}+09$ \\
\hline Contact shear stiffness & $5.00 \mathrm{E}+09$ \\
\hline Ball diameter for block & 0.0005 \\
\hline Thickness of block & 0.006 \\
\hline Friction coefficient between balls & 0.00 \\
\hline
\end{tabular}

\subsection{Model Validation}

To verify the accuracy of the numerical model, the numerical results were compared with other analytical methods and test methods. The geometric shape function of the geomembrane tube is derived, and the relationship between filling pressure and geometric shape is obtained by Leshchinsky et al. (1996). The analysis was calibrated against a geomembrane tube with $L=9 \mathrm{~m}$ and $\gamma=12$ $\mathrm{kN} / \mathrm{m}^{3}$, and inflated with different filling pressures $p_{0}$. The numerical model was also compared to large-scale laboratory model tests conducted by Guo et al. (2014). In this model tests, three geomembrane tubes with dimensions of $1 \mathrm{~m}$ wide by $2 \mathrm{~m}$ long (Model T1), $1.5 \mathrm{~m}$ wide by $3 \mathrm{~m}$ long (Model T2) and $2 \mathrm{~m}$ wide by $4 \mathrm{~m}$ long (Model T3) were inflated by tap water. The height, width and tensile force of the three geomembrane tube under different filling pressures were studied. The $H$ and $B$ values obtained by the above two methods were normalized to obtain the relationship between $H / L, B / L$, and $p_{0} / \gamma L$. The comparison with the calculation results in this paper is shown in Figure 3, and the two results fit well.

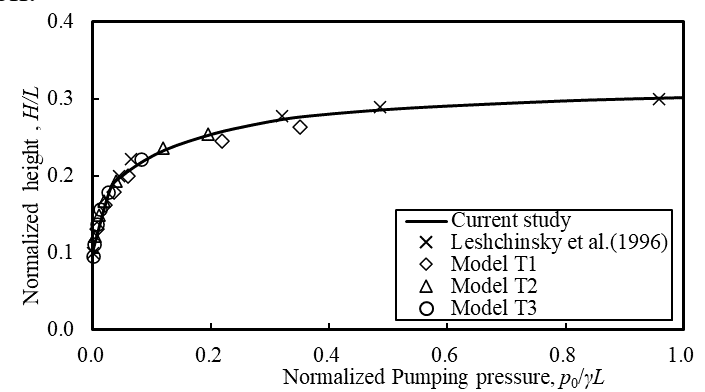

(a) Relationship between $p_{0} / \gamma L$ and $H / L$

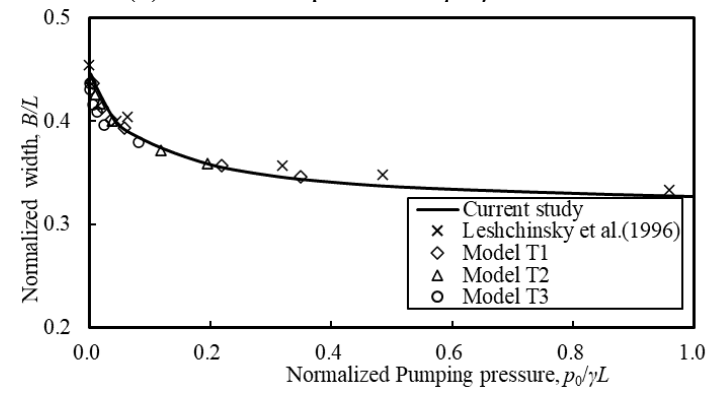

(b) Relationship between $p_{0} / \gamma L$ and $B / L$

Fig.3. Comparison of $\mathrm{PFC}^{2 \mathrm{D}}$ calculated results with existing results

The third comparison is made with the numerical analysis conducted by Huong et al. (2002) using FLAC. The tensile force and cross-sectional shape of the wedged geomembrane tube under different lateral water levels were the mainly studies. The geomembrane tube was modelled with a thickness of $0.508 \mathrm{~mm}$ and perimeter of $L=1.473 \mathrm{~m}$.Tap water was employed as the filling material.When the filling pressure head is $0.465 \mathrm{~m}$, the height of the geomembrane tube is $0.334 \mathrm{~m}$. The lateral water levels were $22.0 \mathrm{~cm}$ and $26.5 \mathrm{~cm}$ when the block height were $6 \mathrm{~cm}$ and $12 \mathrm{~cm}$, respectively. In the current numerical model, the normalized block height was $6 / 1.473 / 100=0.04073,12 / 1.473 / 100=0.0814$, and the normalized lateral water levels were $22 / 1.473 / 100=$ 0.14936 and $26.5 / 1.473 / 100=0.1799$, respectively. The cross-sectional shape of the geomembrane tube obtained by the two methods are shown in Figure 4, which further verifies the rationality of applying the $\mathrm{PFC}^{2 \mathrm{D}}$ to calculating the geomembrane tube.

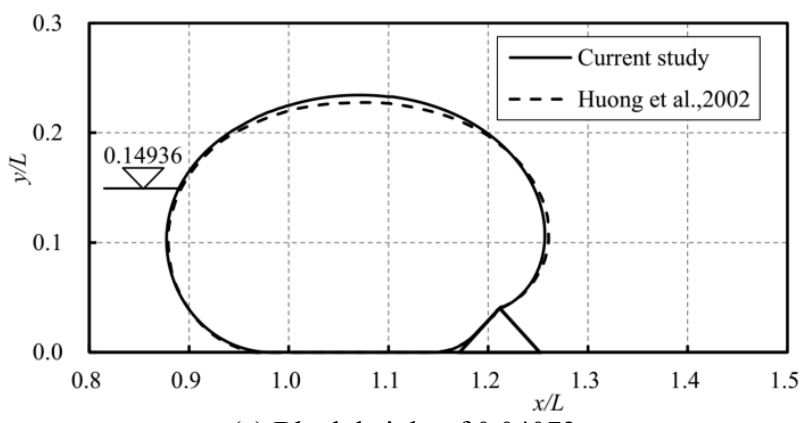

(a) Block height of 0.04073 


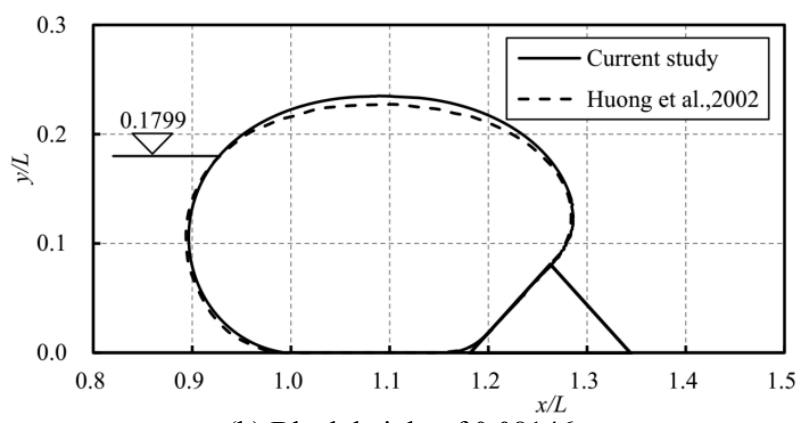

(b) Block height of 0.08146

Fig.4. Comparison the result with Huong et al. (2002)

\section{Research on Overturning Stability}

The force that the L-shaped block bears is determined by the lateral water pressure and the weight of the geomembrane tube. The lateral water pressure pushes the geomembrane tube to roll forward, and finally contacts the block to generate contact force.The free body diagram of the geomembrane tube as shown in Figure $5(\mathrm{a})$, the external load is mainly lateral water pressure. According to the interaction between the geomembrane tube and the block, the free body diagram of the block as shown in Figure 5(b), under the action of the contact force, the block is in a stable state. The lateral water pressure on the geomembrane tube provides the overturning moment $M_{\mathrm{t}}$, while the self-weight of the geomembrane tube and the L-shaped block provide the anti-overturning moment $M_{\mathrm{r}}$. By comparing the values of $M_{\mathrm{r}}$ and $M_{\mathrm{t}}$, it is possible to quantitatively analyze the overturning stability of the L-shaped block.

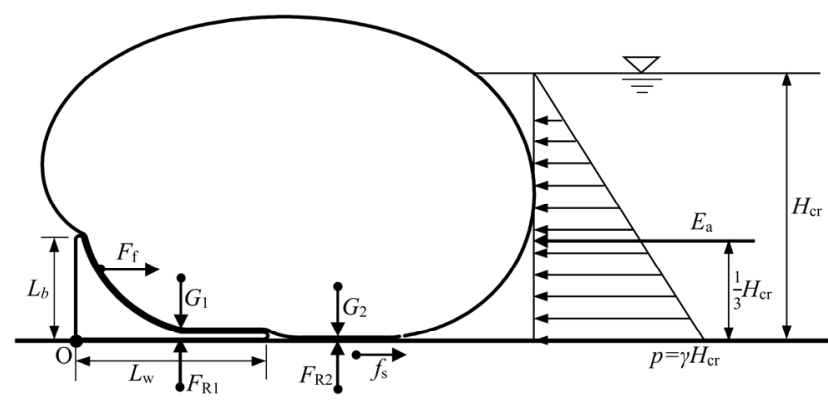

(a) Free body diagram of geomembrane tube

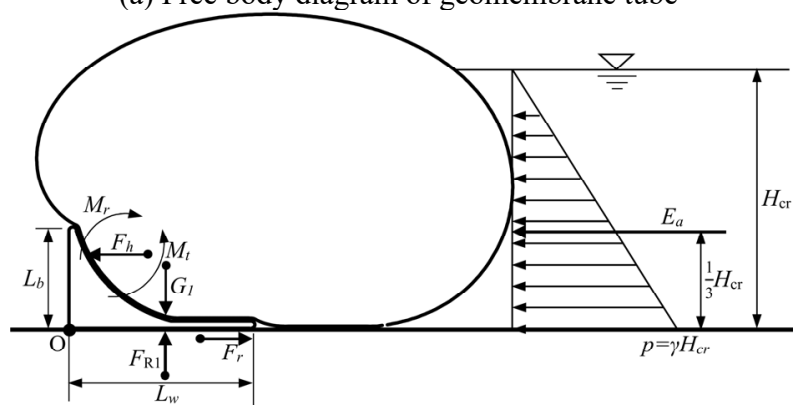

(b) Free body diagram of L-shaped block

Fig.5. Equilibrium of forces acting on the geomembrane tube system

\subsection{Contact force between geomembrane tube and block}

The boundary of the geometric model of the L-shaped block and the geomembrane tube established by the $\mathrm{PFC}^{2 \mathrm{D}}$ is not smooth. The contact force acting between the two entities is the point concentration force. In order to calculate the $M_{\mathrm{t}}$ and $M_{\mathrm{r}}$ of the L-shaped block, it is necessary to convert the point concentration force to the surface force and then integrate the point $O$. In the calculation process, the particle size of the block ball is smaller than that of the geomembrane tube ball. Because the ball is small and the number is large, it is assumed that the normal contact force and the connection line between the balls are perpendicular to each other during the calculation process, as shown in Figure 6 (a). Each block ball represents a micro-element segment, and the concentrated force received by the block ball is equivalent to the uniform force within the diameter of the block ball, as shown in Figure 6 (b). According to the contact force on the block, the starting position of the uniform force at the center point of each ball is connected to obtain the stress distribution form as shown in Figure 6(c). According to the contact stress of the block in Figure 6 (c), the overturning stability of the L-shaped block can be obtained by calculating the moment at point O.

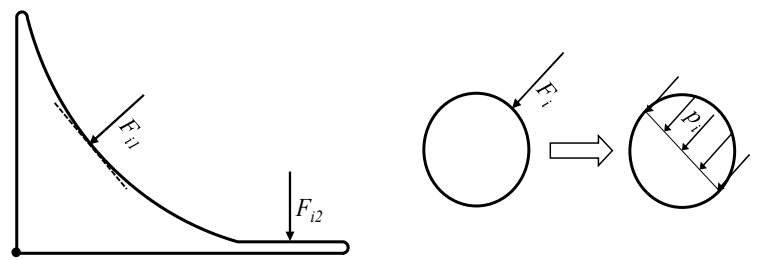

(a) Direction of contact force (b) Contact stress

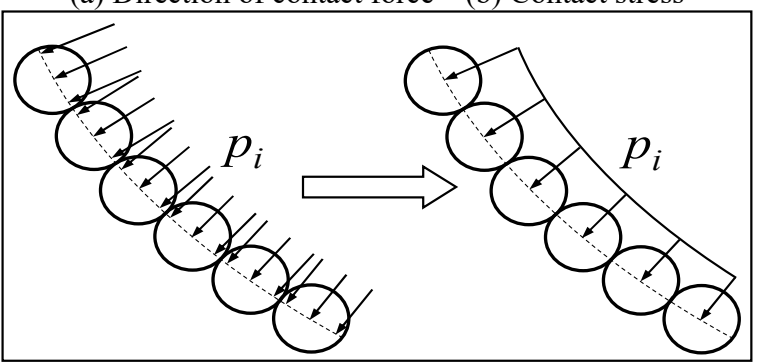

(c) Surface load distribution form

Fig.6. Contact point force equivalent to the surface force

\subsection{Contact Force Distribution Form}

$p_{0} / \gamma L=0.050,0.162, L_{\mathrm{b}} / L=0.08$, and $L_{\mathrm{w}} / L=0.10$ were served as examples to analyze the contact force distribution between the block and the geomembrane tube. The final stable shape of the geomembrane tube under the critical water level is shown in Figure 7. The contact force was extracted from the top to the bottom of the block as shown in Figure 8. It can be seen from Figure 8 that the contact force is non-uniformly distributed along the contact surface, and there is a significant increase in the contact force in segments a and $\mathrm{d}$ at the end of the block. At segment $\mathrm{b}$, the contact force gradually increases with the increase in depth. At segment c, it is uniformly distributed and the hydraulic 
pressure is the largest. According to the composition of forces, the contact force in segment $\mathrm{c}$ is greater than that at the lowest point of segment $\mathrm{c}$. Therefore, there will be a sudden increase in contact force at the transition from the arc-like segment b to the horizontal segment $\mathrm{c}$. In accordance with the force equivalent conversion method in Section 3.1, the contact stress distribution is as shown in Figure 9. It can be seen from Figure 9 that the contact stress in Segments a and $d$ is much larger than that in other segments, which plays a decisive role in the overturning stability of the L-shaped block.

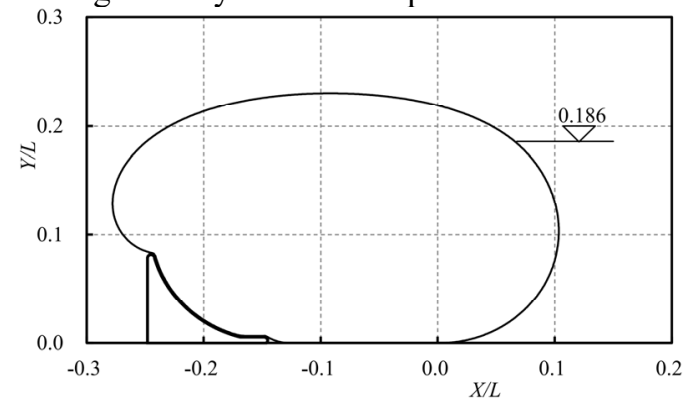

(a) $p_{0} / \gamma L=0.050, H_{\mathrm{cr}} / L=0.186$

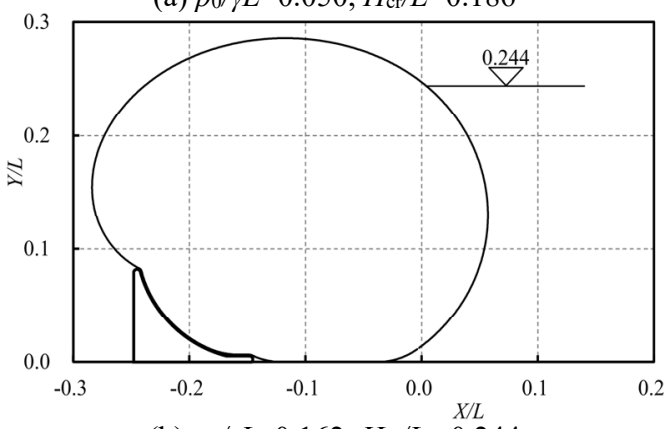

(b) $p_{0} / \gamma L=0.162, H_{\mathrm{cr}} / L=0.244$

Fig.7. Final Motion of the geomembrane Tube

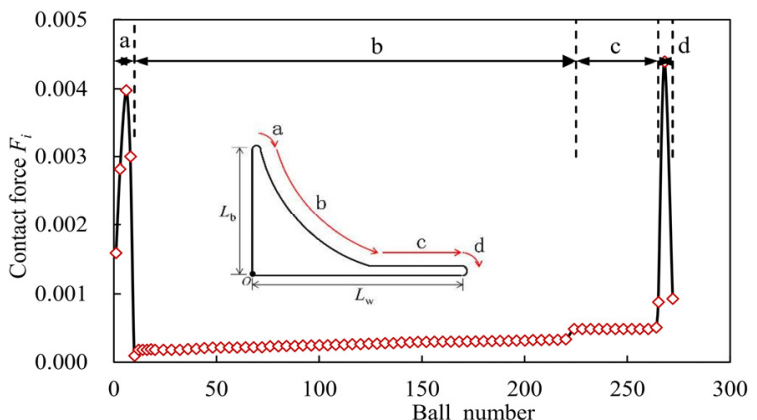

(a) $p_{0} / \gamma L=0.050, H_{\mathrm{cr}} / L=0.186$

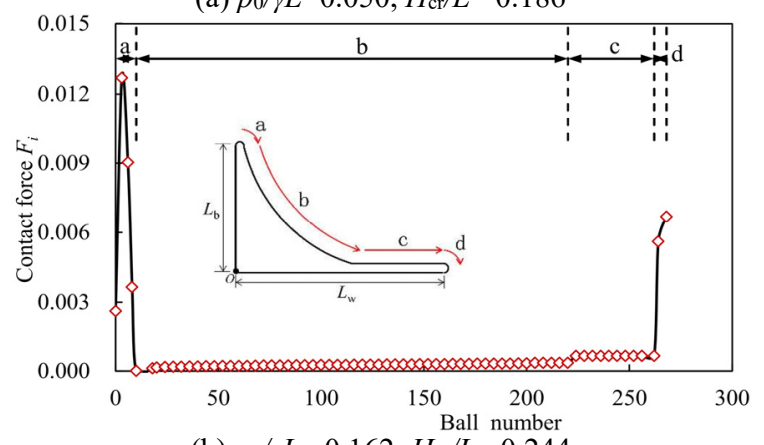

(b) $p_{0} / \gamma L=0.162, H_{\mathrm{cr}} / L=0.244$

Fig.8. Contact force distribution

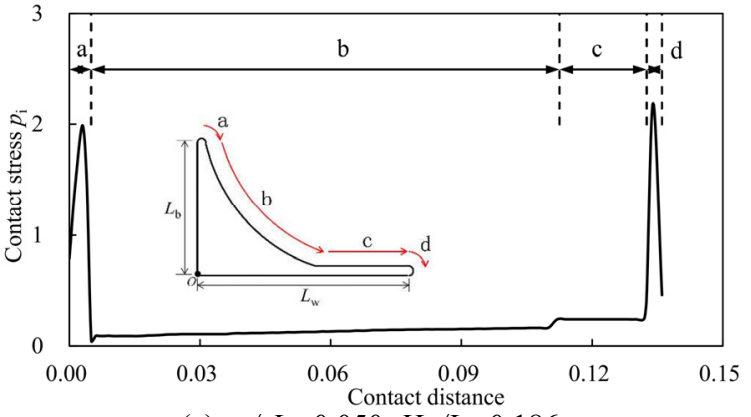

(a) $p_{0} / \gamma L=0.050, H_{\mathrm{cr}} / L=0.186$

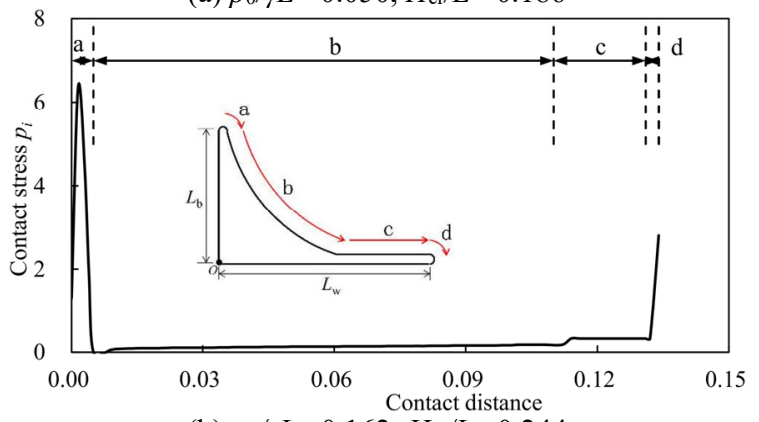

(b) $p_{0} / \gamma L=0.162, H_{\mathrm{cr}} / L=0.244$

Fig.9. Contact stress distribution on the block surface

According to Figure 9, the contact stress can be plotted on the block, and the contact stress distribution on the block is shown in Fig. 10(a). In order to obtain the overturning moment and anti-overturning moment at point $\mathrm{O}$, the stress in the contact range is divided into four parts from top to bottom, which are the top of the block, the inner arc segment, the bottom horizontal segment, and the bottom toe as shown in Figure 10(b). The overturning moment and anti-overturning moment are obtained by calculating the moments of the four partial stresses to point $\mathrm{O}$, as shown in Equations 5 8. Finally, the anti-overturning moment $M_{\mathrm{r}}=M_{1 \mathrm{r}}+M_{2 \mathrm{r}}+M_{3 \mathrm{r}}+M_{4 \mathrm{r}}$ and the overturning moment $M_{\mathrm{t}}=M_{1 \mathrm{t}}+M_{2 \mathrm{t}}+M_{4 \mathrm{t}}$ are calculated to obtain the antioverturning stability coefficient $K_{\mathrm{p}}=M_{\mathrm{r}} / M_{\mathrm{t}}$ of the Lshaped block.

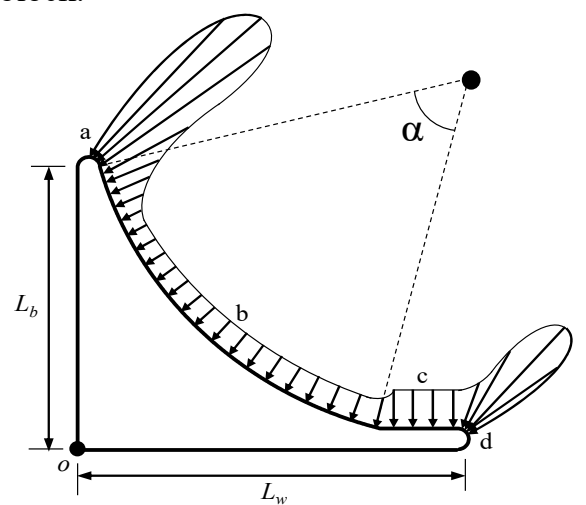

(a) Contact stress distribution 


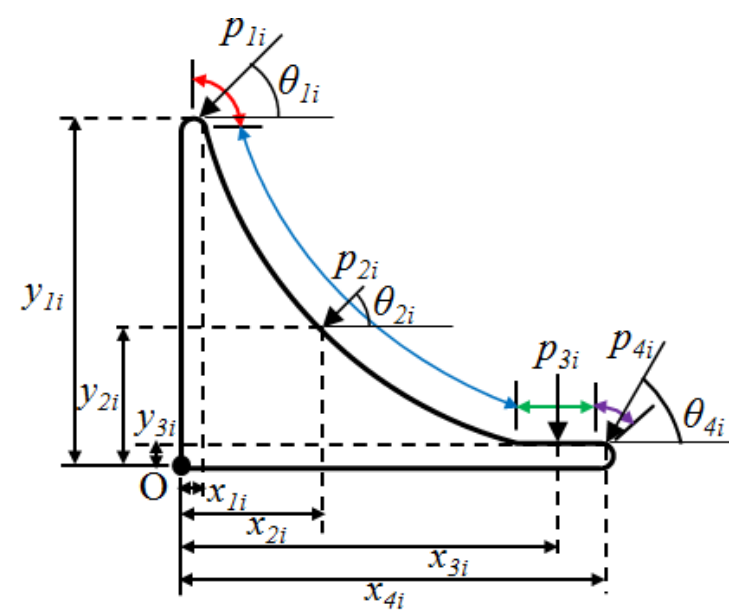

(b) Calculation of stress moments to point $\mathrm{O}$

Fig.10.Simplified diagram of stress distribution and moment calculation in contact sections

$$
\begin{gathered}
\left\{\begin{array}{l}
M_{1 r}=\int p_{1 i} \sin \theta_{1 i} x_{1 i} d x \\
M_{1 t}=\int p_{1 i} \cos \theta_{1 i} y_{1 i} d y
\end{array}\right. \\
\left\{\begin{array}{l}
M_{2 r}=\int p_{2 i} \sin \theta_{2 i} x_{2 i} d x \\
M_{2 t}=\int p_{2 i} \cos \theta_{2 i} y_{2 i} d y
\end{array}\right. \\
M_{3 r}=\int p_{3 i} x_{3 i} d x \\
\left\{\begin{array}{l}
M_{4 r}=\int p_{4 i} \sin \theta_{4 i} x_{4 i} d x \\
M_{4 t}=\int p_{4 i} \cos \theta_{4 i} y_{4 i} d y
\end{array}\right.
\end{gathered}
$$

\section{Parameter Analysis}

\subsection{Central Angle of the L-shaped Block}

$L_{\mathrm{w}} / L_{\mathrm{b}}=1.25\left(L_{\mathrm{b}} / L=0.08\right)$ and $L_{\mathrm{w}} / L_{\mathrm{b}}=1.4\left(L_{\mathrm{b}} / L=0.10\right)$ were taken as examples to analyze the impact of $\alpha$ on $K_{\mathrm{p}}$. In the calculation process, the critical water level acted as the lateral water level. When $L_{\mathrm{w}} / L_{\mathrm{b}}=1.25$ and $p_{0} / \gamma L=$ 0.087 , the final motions of the geomembrane tube under different central angles are shown in Figure 11. It can be seen from the figure that $\alpha$ has little impaction on the critical water level, but when $\alpha$ increases, the contact range of the geomembrane tube and the block increases significantly and the gap range gradually decreases.

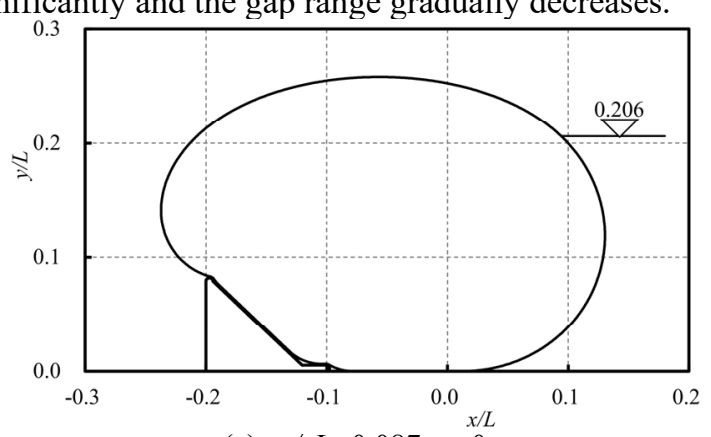

(a) $p_{0} / \gamma L=0.087, \alpha=0$

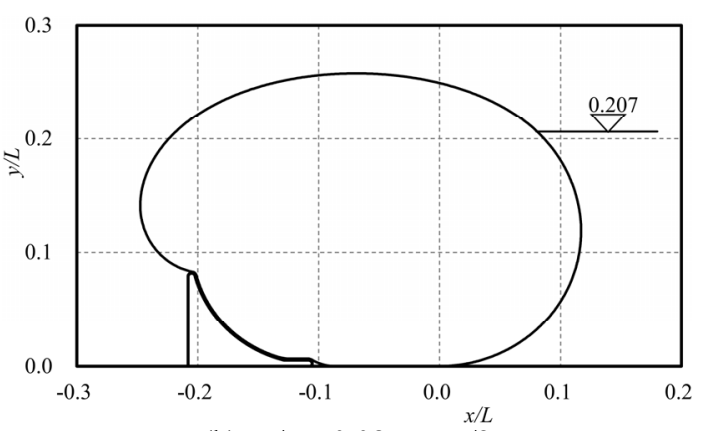

(b) $p_{0} / \gamma L=0.087, \alpha=\pi / 2$

Fig.11. Final motion of geomembrane tube under different central angle

Assuming $p_{0} / \gamma L=0.05 \sim 0.244$, the relationship between $\alpha$ and $K_{\mathrm{p}}$ is shown in Figure 12. It can be seen that when $\alpha$ is increased, $K_{\mathrm{p}}$ will increase because in segment $b$, the contact force range is shifted from the upper half of segment $b$ to the entire segment $b$ or separated from the entire segment $b$. The contact range increases in segment $\mathrm{c}$ and the contact force in segment $\mathrm{d}$ gradually increases, causing $M_{\mathrm{r}}$ to increase, as shown in Figure 13. When $\alpha=0 \sim \pi / 3$, the impact on $K_{\mathrm{p}}$ is small, and the secant slope is $0.086 \sim 0.105$. In the process of $\pi / 3 \sim \pi / 2$, $\alpha$ has a great impact on $K_{\mathrm{p}}$, and the slope of the secant line is $0.191 \sim 0.302$. $K_{\mathrm{p}}$ varies between 0.19 and 0.22 when $\alpha$ changes, indicating that $\alpha$ has a small impact on $K_{p}$. It can be seen from Figure 13 that when $p_{0} / \gamma L$ is small, the increase in $\alpha$ can further exaggerate the contact range between the geomembrane tube and the block and reduce the gap range between them; on the contrary, if $p_{0} / \gamma L$ is large, the increase in $\alpha$ may further reduce the contact range between the geomembrane tube and the block, and expand the gap range between them.

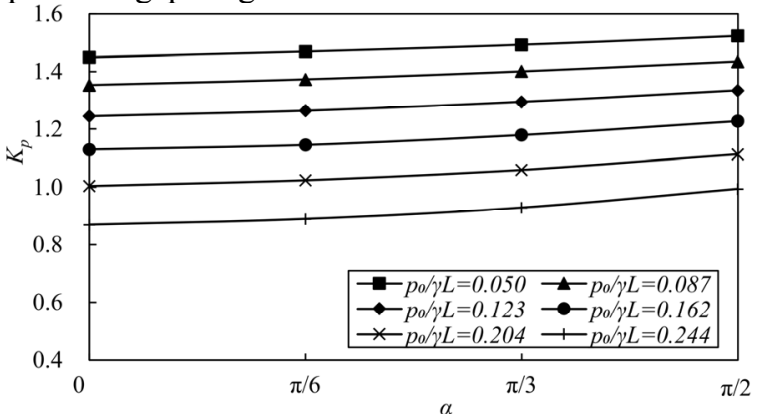

(a) Impact of $\alpha$ on $K_{\mathrm{p}}$ when $L_{\mathrm{w}} / L_{\mathrm{b}}=1.25$

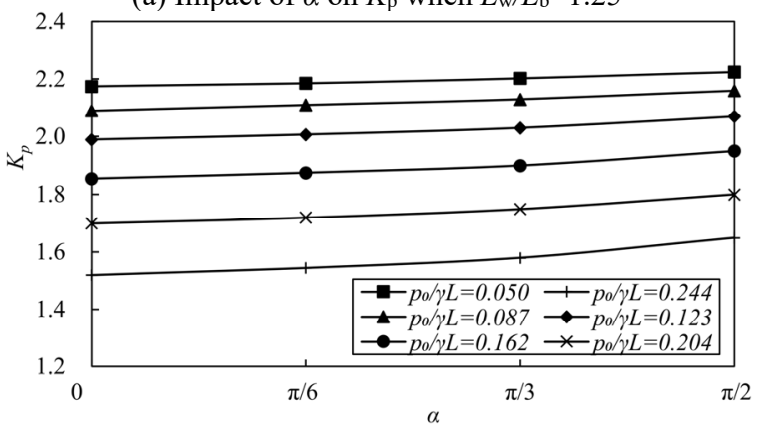

(b) Impact of $\alpha$ on $K_{\mathrm{p}}$ when $L_{\mathrm{w}} / L_{\mathrm{b}}=1.4$

Fig.12. The relationship between $\alpha$ and $K_{\mathrm{p}}$ 


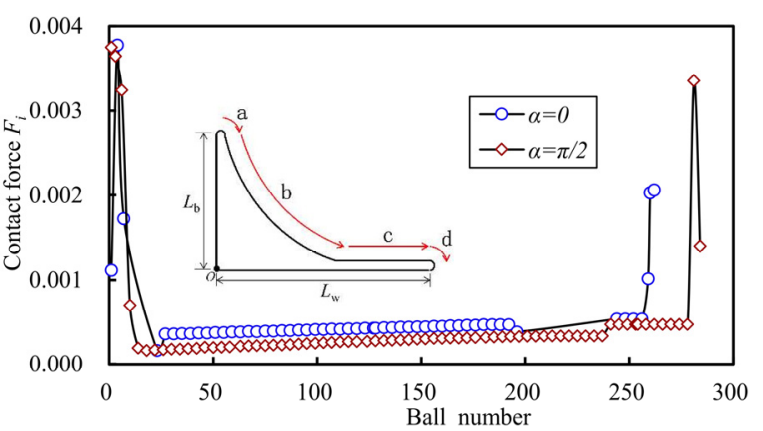

(a) $p_{0} / \gamma L=0.050$

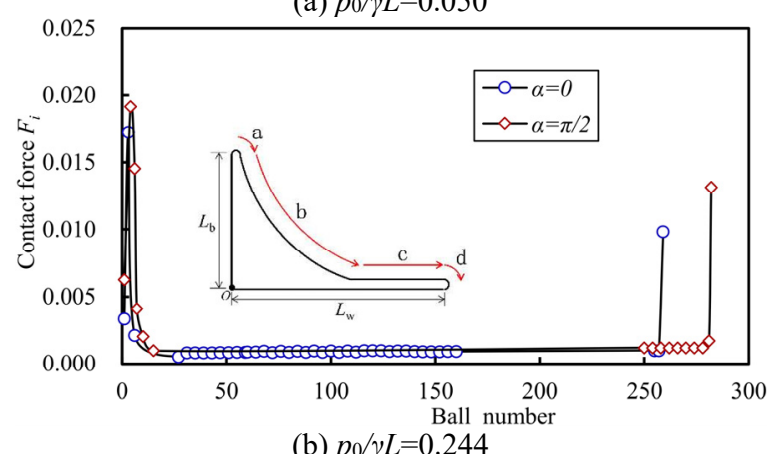

Fig.13. Contact force distribution with different central angles

\subsection{Filling Pressure}

The filling pressure significantly affects the geometry, self-weight, and water retaining Water performance of the geomembrane tube, and the overturning stability of the block will be impact indirectly. Assuming $p_{0} / \gamma L=$ $0.050 \sim 0.244, \alpha=0 \sim \pi / 3, L_{\mathrm{w}} / L_{\mathrm{b}}=1.25\left(L_{\mathrm{b}} / L=0.08\right)$, $L_{\mathrm{w}} / L_{\mathrm{b}}=1.4\left(L_{\mathrm{b}} / L=0.10\right)$, when the lateral water level is the critical water level, the relationship between $K_{\mathrm{p}}$ and $p_{0} / \gamma L$ is shown in Figure 14. It can be seen from the figure that when $p_{0} / \gamma L$ increases, $K_{\mathrm{p}}$ gradually decreases because the enhancement of the geomembrane tube stiffness increases the critical water level during $p_{0} / \gamma L$ is increasing, which leads to a significant increase in the contact force of segment a of the block, thereby increasing $M_{\mathrm{t}}$, as shown in the Figure. 15. From Figure 15 , with the increase of $p_{0} / \gamma L$, the contact force range gradually shifts to the two directions: Segments a and $d$ of the block because when $p_{0} / \gamma L$ is large, the geomembrane tube is not easy to deform, and in segments $\mathrm{b}$ and $\mathrm{c}$, the geomembrane tube does not contact with the block in a large area.

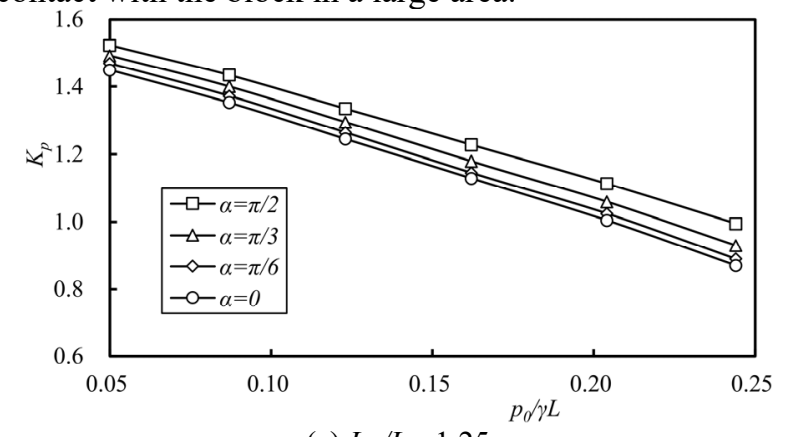

(a) $L_{\mathrm{w}} / L_{\mathrm{b}}=1.25$

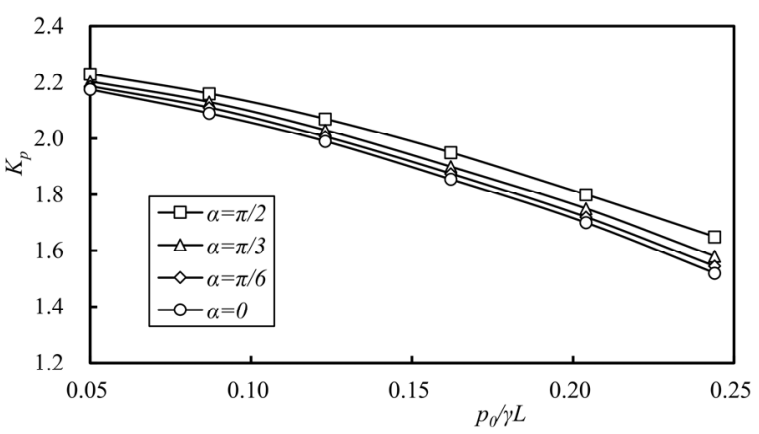

(b) $L_{\mathrm{w}} / L_{\mathrm{b}}=1.4$

Fig.14. The relationship between $p_{0} / \gamma L$ and $K_{\mathrm{p}}$

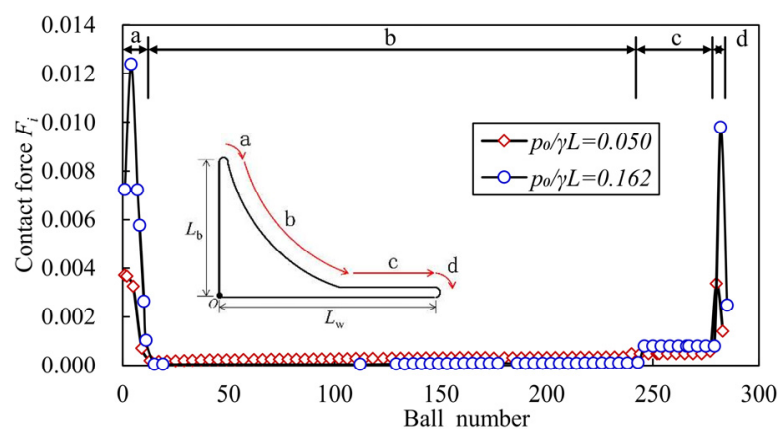

(a) Contact force distribution When $\alpha=0$

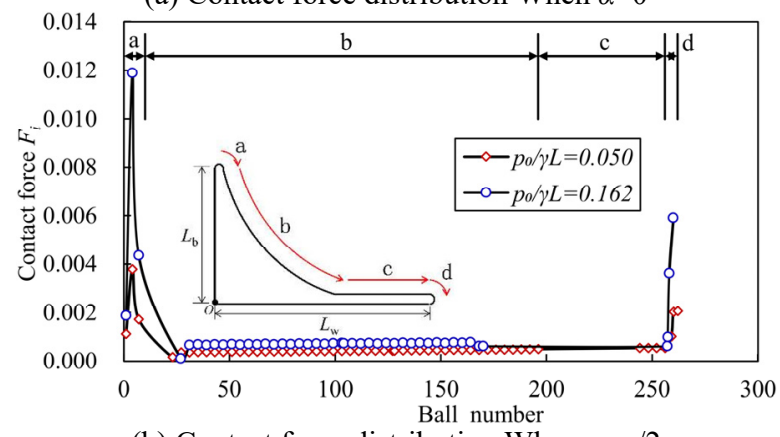

(b) Contact force distribution When $\alpha=\pi / 2$

Fig.15. Contact force distribution under different $p_{0} / \gamma L$

\subsection{Height of the L-shaped Block}

$L_{\mathrm{w}} / L_{\mathrm{b}}=1.4\left(L_{\mathrm{b}} / L=0.06,0.08,0.10,0.12,0.14\right), p_{0} / \gamma L=$ $0.050 \sim 0.244$ were served as examples to analyze the impact of $L_{\mathrm{b}} / L$ on $K_{\mathrm{p}}$. When $p_{0} / \gamma L=0.050$ and $L_{\mathrm{b}} / L=$ $0.06,0.14$, the final motion of the geomembrane tube is shown in Figure 16. It can be seen from the figure that when $L_{\mathrm{b}} / L=0.06$, the critical water level is less than the height of the geomembrane tube, and when $L_{\mathrm{b}} / L=0.14$, the critical water level is equal to the height of the geomembrane tube, indicating that there is a critical value for $L_{\mathrm{b}} / L$. When it is greater than the critical value, $H_{\mathrm{cr}} / L$ is equal to the height of the geomembrane tube, on the contrary, $H_{\mathrm{cr}} / L$ is less than the height of the geomembrane tube. Under different working conditions, the relationship between $L_{\mathrm{b}} / L$ and $K_{\mathrm{p}}$ is shown in Figure 17. It can be seen from the figure that as $L_{\mathrm{b}} / L$ increases, $K_{\mathrm{p}}$ increases non-linearly. There are two main reasons: firstly, when $L_{\mathrm{b}} / L$ increases, the $M_{\mathrm{r}}$ provided by segment c of the block increases; and secondly, the larger $p_{0} / \gamma L$, the smaller the critical height of the block. When $L_{\mathrm{b}} / L$ is greater than the critical height, the contact force on segment a of the block is significantly reduced or 
becomes zero, and the contact force gradually shifts to segment $\mathrm{b}$ and $\mathrm{c}$, which causes $M_{\mathrm{t}}$ to decrease and $M_{\mathrm{r}}$ to increase, and $K_{\mathrm{p}}$ increases accordingly.

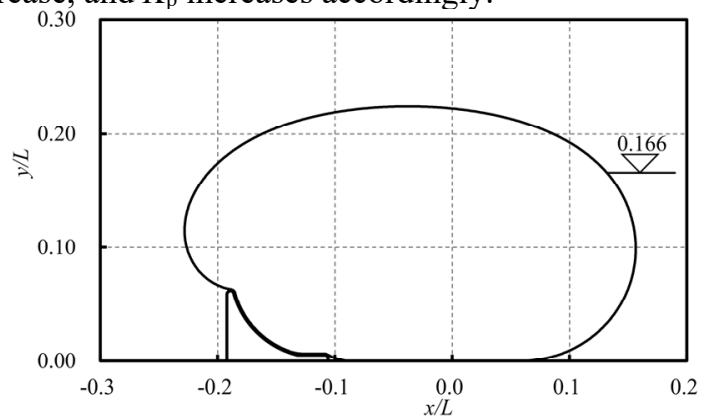

(a) $L \mathrm{~b} / L=0.06$

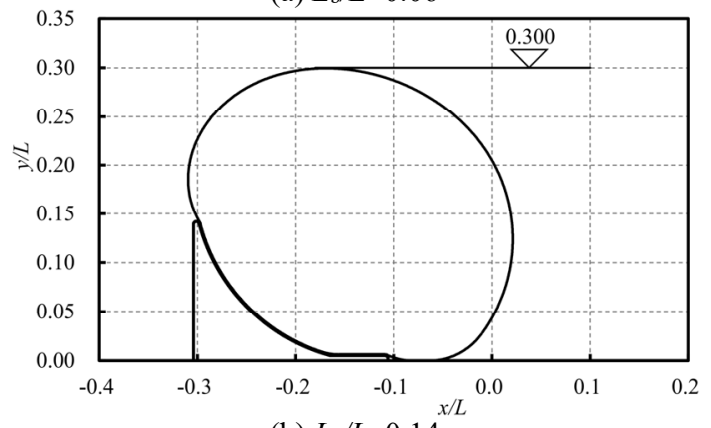

(b) $L_{\mathrm{b}} / L=0.14$

Fig.16. Final motion of the geomembrane tube with different block heights $\left(p_{0} / \gamma L=0.050\right)$

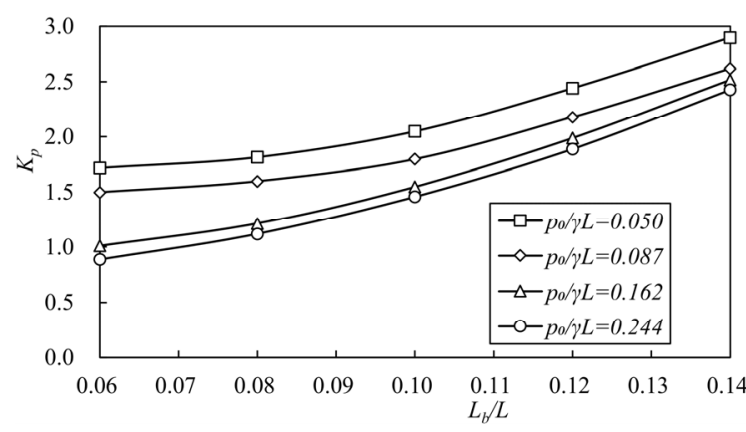

Fig.17. Relationship between $L \mathrm{~b} / L$ and $K_{\mathrm{p}}$

\subsection{Width of the L-shaped Block}

With different $p_{0} / \gamma L$, the geomembrane tube corresponds to a critical block height $L_{\mathrm{bcr}} / L$ and an extreme water level $H_{\mathrm{ext}} / L . L_{\mathrm{bcr}} / L$ means that when the lateral water level is equal to the height of the geomembrane tube, geomembrane tube just does not overturn. When $L_{\mathrm{b}} / L=$ $L_{\mathrm{w}} / L$, the relationship between $H_{\mathrm{cr}} / L$ and $L_{\mathrm{b}} / L$ under different $p_{0} / \gamma L$ is shown in Figure 18. It can be seen from the figure that under different $p_{0} / \gamma L$ there is a $H_{\mathrm{ext}} / L$ under $L_{\mathrm{bcr}} / L$ as shown by the CSL line in the figure. With the increase of $p_{0} / \gamma L, L_{\mathrm{bcr}} / L$ decreases at an increasing rate, and $H_{\text {ext }} / L$ increases at a decreasing rate.

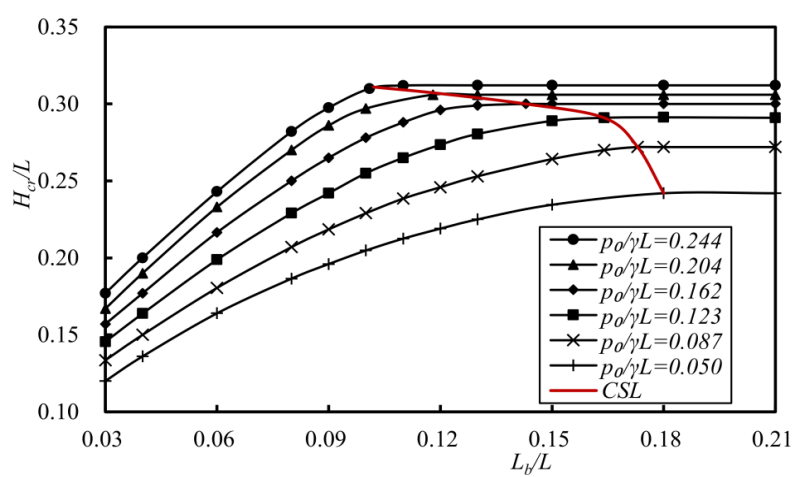

Fig.18. Relationship between $H_{\mathrm{cr}} / L$ and $L_{\mathrm{b}} / L$

In order to study the overturning stability of the Lshaped block, it is necessary to calculate its overturning stability on the CSL line and determine the block width just at the critical state of overturning. Assuming $p_{0} / \gamma L=$ $0.050 \sim 0.244$ and $L_{\mathrm{w}} / L_{\mathrm{bcr}}=1.0 \sim 2.0$, the relationship between $K_{p}$ and $L_{\mathrm{w}} / L_{\mathrm{bcr}}$ is analyzed, as shown in Figure 19 . It can be seen that when $L_{\mathrm{w}} / L_{\mathrm{bcr}}$ is increased, $K_{\mathrm{p}}$ first increases and then tends to a stable value. After that, increasing $L_{\mathrm{w}} / L_{\mathrm{bcr}}$ has little effect on $K_{\mathrm{p}}$. When $L_{\mathrm{w}} / L_{\mathrm{b}}=$ 1.0 , and $K_{\mathrm{p}}=1.0, p_{0} / \gamma L=0.152$, which means that when $p_{0} / \gamma L<0.152$, the L-shaped block is in a stable state of overturning, and when $p_{0} / \gamma L \geq 0.152, L_{w} / L_{b c r}$ can only guarantee its overturning stability when it reaches a certain value. Under different $p_{0} / \gamma L$, when $L_{\mathrm{w}} / L_{\mathrm{bcr}} \geq 1.23$, the L-shaped block is in a stable state of overturning, and $K_{p}$ remains unchanged when $L_{\mathrm{w}} / L_{\mathrm{bcr}} \geq 1.55$, indicating that the geomembrane tube is all located on the block at this time, so the optimal range of the block width is 1.23 $L_{\mathrm{bcr}} \leq L_{\mathrm{w}} \leq 1.55 L_{\mathrm{bcr}}$. A polynomial model is employed to fit Fig. 19 to get equation (9) and $\mathrm{R}^{2}=0.994$, which shows that this equation can be applied to the simplified calculation of the stability of the L-shaped block.

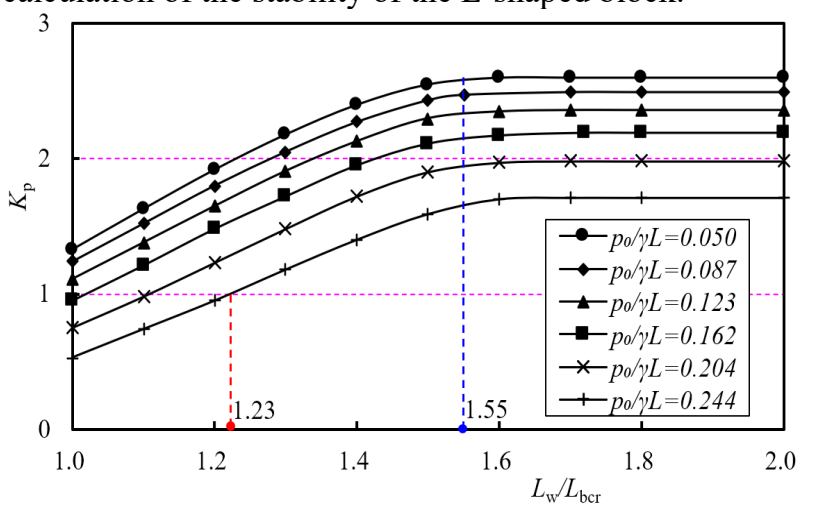

Fig.19. Relationship between $L_{\mathrm{w}} / L_{\mathrm{b}}$ and $K_{\mathrm{p}}$

$$
\begin{aligned}
K_{\mathrm{p}} & =-2.0534\left(\frac{L_{\mathrm{w}}}{L_{\mathrm{b}}}\right)^{2}+7.3873\left(\frac{L_{\mathrm{w}}}{L_{\mathrm{b}}}\right)-1.2859\left(\frac{p_{0}}{\gamma L}\right)^{2}-3.8881\left(\frac{p_{0}}{\gamma L}\right) \\
R^{2} & =0.994
\end{aligned}
$$

\section{Conclusion}

Based on the particle flow code $\left(\mathrm{PFC}^{2 \mathrm{D}}\right)$, the overturning stability of L-shaped geomembrane tube system have been investigated. The impacts of central angle, filling 
pressure, block height and width on the overturning stability of L-shaped blocks are analyzed. Based on the polynomial model, the overturning stability coefficient has fitted and drawn the following conclusions:

The contact force between the geomembrane tube and the block is unevenly distributed. When $\alpha=0 \sim \pi / 2$, the difference between $K_{\mathrm{p}}$ is between 0.19 and 0.22 , indicating that $\alpha$ has little effect on $K_{\mathrm{p}}$. Increasing $p_{0} / \gamma L$, $K_{\mathrm{p}}$ decreases significantly. When $L_{\mathrm{w}} / L_{\mathrm{b}}$ remains unchanged, increase $L_{\mathrm{b}} / L$ and $K_{\mathrm{p}}$ increases nonlinearly. Under the extreme water level, when $L_{\mathrm{w}}>1.23 L_{\mathrm{bcr}}$, the block is in a stable state of overturning. When $L_{\mathrm{w}}>1.55$ $L_{\text {bcr, }}$ all the geomembrane tubes are located above the block, and the optional width range of the block is 1.23 $L_{\text {bcr }}<L_{\mathrm{w}} \leq 1.55 L_{\mathrm{bcr}}$. When $p_{0} / \gamma L<0.152 \gamma L$, the block is in a stable state of overturning. When $p_{0} / \gamma L>0.152 \gamma L$, $L_{w} / L$ can only guarantee its overturning stability when it reaches a certain value. Based on the polynomial curve model, the fitting equation $\left(\mathrm{R}^{2}=0.994\right)$ is obtained between $p_{0} / \gamma L$ with $K_{\mathrm{p}}$ and $L_{\mathrm{w}} / L_{\mathrm{bcr}}$, and a simplified calculation method is proposed for overturning stability.

\section{Acknowledgments}

The funding supports from the National Natural Science Foundation of China (51878446, 52078336) and the Nature and Scientific Fund Project in Tianjin (18JCYBJC40500, 19JCYBJC22100) and the Tianjin Science and Technology Plan Project(20JCJQJC00220).

\section{References}

1 Biggar, K., and Masala, S. (1998). Alternatives to sandbags for temporary flood protection. Technical report. Disaster Services Branch, Alberta Transportation and Utilities, Canada.

2 Fowler, J. (1997). Geotexitile tubes and flood control. Geotechnical Fabrics Report,15(5):28-37.

3 Leshchinsky, D., Leshchinsky, O., Ling, H. I., and Gilbert, P. A. (1996). Geosynthetic tubes for confining pressurized slurry: Some design aspects. Journal of Geotechnical Engineering, 122(8): 682690.

4 Plaut, R. H., and Suherman,S. (1998). Twodimensional analysis of geosynthetic tubes. Acta Mechanica 129 (3):207-18.

5 Cantré, S., and Saathoff, F. (2011). Design method for geotextile tubes considering strain-formulation and verification by laboratory tests using photogrammetry. Geotextiles and Geomembranes 29 (3):201-10.

6 Guo, W., Chu, J., and Nie, W. (2014). A simplified method for the design of geosynthetic tube. Geotextiles and Geomembranes, 42(5):421-427.

7 Guo, W., Chu, J., and Nie, W. (2014). Analysis of geosynthetic tubes inflated by liquid and consolidated soil[J]. Geotextiles and Geomembranes, 42(4):277-283.
8 Guo, W., Chu, J., Yan, S., and Nie, W.( 2013). Geosynthetic mattress: Analytical solution and verification $[\mathrm{J}]$. Geotextiles and Geomembranes, 37:87-80.

9 Guo, W., Chu, J., and Yan, S. (2011). Effect of subgrade soil stiffness on the design of geosynthetic tube. Geotextiles and Geomembranes, 29(3), 277284.

10 Cantré,S. (2002). Geotextile tubes-analytical design aspects[J]. Geotextiles and Geomembranes, 20(5):305-319.

11 Plaut, R. H., and Klusman, C.R.(1999). Twodimensional analysis of stacked geosynthetic tubes on deformable foundations. Thin-Walled Structures 34(3):179-194.

12 Ghavanloo, E., and Daneshmand, F. (2008). Twodimensional analytical analysis of equilibrium shape of inflated geomembrane tube resting on rigid foundation with arbitrary shape[J]. Geotextiles and Geomembranes, 27(2):99-106.

13 Malík Josef. (2007). Some problems connected with 2D modeling of geosynthetic tubes[J]. Nonlinear Analysis: Real World Applications, 10(2):810-823.

14 Malik Josef., and Stanislav Sysala. (2010). Analysis of geosynthetic tubes filled with several liquids with different densities[J]. Geotextiles and Geomembranes, 29(3):249-256.

15 Huong, T. C., Plaut, R. H., and Filz, G. M. (2002). Wedged geomembrane tubes as temporary floodfighting devices. Thin-Walled Structures, 40(11), 913-923.

16 Kim, M., Freeman, M., FitzPatrick, B. T., Nevius, D. B.,Plaut, R. H., and Filz, G. M. (2004). Use of an apron to stabilize geomembrane tubes for fighting floods. Geotextiles and Geomembranes, 22(4):239254.

17 Kim, M., M. Moler, M. Freeman, G. M. Filz, and R. H. Pluaut. (2005b). Stacked geomembrane tubes for flood control: experiments and analysis. Geosynthetics International 12 (5): 253-259.

18 Kim, M., Filz, G. M., and Plaut, R. H. (2005). Twochambered water filled geomembrane tubes used as water barriers: Experiments and analysis. Geosynthetics International, 12(3):127-133.

19 Sun, L., Yue, C., and Guo, W. (2017). Lateral stability analysis of wedged geomembrane tubes using PFC2D. Marine Georesources and Geotechnology, 35(5):730-737.

20 Sun L., Qi Y., Gao X., Guo, W., and Zhang N. (2019). Stability of supported geomembrane tube flood barriers of novel design[J]. Journal of Flood Risk Management,13(1):1-10. 